\title{
EL MERCADO ESCOLAR EN CHILE Y EL SURGIMIENTO DE LA NUEVA GESTIÓN PÚBLICA: EL TEJIDO DE LA POLÍTICA ENTRE LA DICTADURA NEOLIBERAL Y LOS GOBIERNOS DE LA CENTROIZQUIERDA (1979 A 2009)
}

\author{
Alejandra Falabella
}

RESUMEN: El presente artículo examina las distintas fases en las que se ha edificado el mercado escolar y la Nueva gestión pública en Chile, de 1979 a 2009. Este proceso se ha dibujado paulatinamente, transitando de un "mercado salvaje" hacia un mercado preformativo, arbitrado por el Estado, que combina soportes programáticos y curriculares, con una compleja matriz institucional de evaluación, inspección y rendición de cuentas. La Nueva Gestión Pública (NGP) se consolida como un acuerdo entre las coaliciones de derecha y centroizquierda, comprendido como salvaguardia de las desregulaciones y "fallas" del sistema mercantil. Los cambios no significan la reducción de un esquema de mercado, sino que más bien su mantención y sofisticación, por medio de nuevos dispositivos de control, diferenciación y competencia. A partir de la indagación de los discursos oficiales y escritos de la época, el estudio ofrece un análisis de las políticas que tejen el modelo y las narrativas que le dan sustento.

Palabras clave: Nueva gestión pública; Mercado escolar; Estado evaluador; Chile.

\section{SCHOOL MARKETS IN CHILE AND THE EMERGENCE OF THE NEW PUBLIC MANAGEMENT: THE FABRIC OF POLICIES BETWEEN A NEOLIBERAL DICTATORSHIP REGIME AND CENTER-LEFT DEMOCRATIC GOVERNMENTS (1979-2009)}

\begin{abstract}
This paper examines the different phases in which school markets and New public management have been built in Chile, from 1979 to 2009 . The process is gradually designed to move from a "wild market" to a performative market arbitrated by the state. The governance scheme combines programmatic and curricular support, together with an extensive accountability system. Emerging from an
\end{abstract}

\footnotetext{
* Universidad Alberto Hurtado, Centro de Investigación y Desarrollo en Educación. Santiago, Chile. E-mail de contacto: afalabel@uahurtado.cl.
} 
agreement between right and center-left coalitions, NPM is understood as a safeguard against the deregulation and "failures" of the educational market. These changes, however, actually reaffirm the maintenance and enhancement of the market schema through new technologies of control, differentiation and competition. Based on the study of official speeches and documents of this historical period, the article provides an analysis of the policies that create the model and the narratives that give it sustenance.

Keywords: School market; New public management; State evaluator; Chile.

\section{L'HISTOIRE DU MARCHÉ SCOLAIRE AU CHILI ET L'ÉMERGENCE DE LA NOUVELLE GESTION PUBLIQUE: LE TISSU POLITIQUE DE LA DICTATURE NÉO-LIBÉRALE ET DES GOUVERNEMENTS DE CENTRE-GAUCHE (1979-2009)}

RÉSUMÉ: Cet article examine les différentes étapes de la construction du marché scolaire et de la Nouvelle Gestion Publique au Chili de 1979 à 2009. Ce processus a été décrit lentement, passant d'un «marché sauvage» à un marché préformatif, dirigé par l'État combinant des supports programmatiques et scolaires, à un ensemble complexe d'évaluation institutionnelle, d'inspection et de reddition de comptes. La NGP est vue comme un accord entre les coalitions de droite et de centre-gauche, comprise comme une garantie de la déréglementation et de "manque» dans le marché de l'éducation. Les changements ne représentent pas la réduction d'un régime de commercialisation, mais si son entretien et sophistication à travers les nouveaux dispositifs de contrôle, de différenciation et de compétence. À partir des discours et des documents officiels de l'époque, nous y fournissons une analyse des politiques qui tissent le modèle et les récits qui le soutiennent.

Mots-clés: Nouvelle gestion publique; Marché de l'école; État évaluateur; Chili.

\section{Introducción ${ }^{1}$}

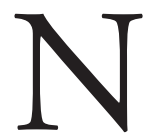

o existe una fórmula única de mercado escolar. El caso chileno ilustra distintas versiones de esta nomenclatura en educación, que ha fluctuado entre un régimen dictatorial y gobiernos democráticos de centroizquierda y de derecha. Los discursos y dispositivos políticos que configuran un esquema de este tipo se han sofisticado con el tiempo, trasladándose desde un "mercado salvaje", con un proyecto de privatización y control autoritario- 
-conservador, hacia un mercado preformativo, en que se consolida un Estado supervigilante orientado por los principios de la Nueva gestión pública (NGP).

Este estilo de gobernanza, en el caso chileno, implica la configuración de un mercado escolar que desregula la entrada de proveedores privados, fragmenta la provisión pública al descentralizar su gestión y crea incentivos para un funcionamiento competitivo vía elección de los padres y financiamiento a la demanda. El Estado abandona así su papel de proveedor centralizado y asume uno subsidiario, mientras coordina el sistema por medio de la definición del curriculum y estándares nacionales, de la evaluación, clasificación y difusión del desempeño de los establecimientos, y de la fijación de consecuencias (premios, sanciones, condiciones) ligadas a dichos resultados evaluativos.

El Estado, lejos de reducir su poder, define y regula las reglas del juego en la esfera del mercado escolar. (NEWMAN, 2005; CLARKE; NEWMAN, 1997) Entabla una relación contractual con los establecimientos educativos, entregando un subsidio a cambio del cumplimiento de estándares e indicadores de logro. El Estado direcciona, así, una dispersa red de proveedores, públicos y privados, ejerciendo, en palabras de Rose y Miller (1992), un "poder a la distancia", lo que también se conceptualiza como "Estado evaluador”. (MAROY, 2009)

El diseño descrito dibuja un mercado preformativo que implica una doble rendición de cuentas. (FALABELLA, 2014) Por una parte, los establecimientos deben rendirle cuentas al mercado, dando respuesta a la demanda de las familias y así captar mayor matrícula. Por otra parte, las instituciones escolares deben rendir cuentas al Estado por el cumplimiento de estándares y metas de desempeño. En lo más profundo, esta perspectiva cambia el ethos de la escuela, inyectando a un bien público, como es la educación, una lógica empresarial basada en principios de competencia, riesgo, cumplimiento de metas cuantificables e incentivos ligados a resultados.

Este artículo ofrece un análisis de las políticas que tejen este modelo y las narrativas que le dan sustento. En este contexto, la NGP será entendida desde la perspectiva de Foucault (2008), no como un conjunto de dogmas, sino como un proyecto político, con principios, discursos y prácticas que crean el mundo social como una verdad. El siguiente análisis estudia no solamente el diseño de las políticas educativas y sus transformaciones a través del tiempo, sino también la reorganización de las racionalidades politicas, sus continuidades, giros y quiebres.

El estudio se inicia con el análisis del régimen dictatorial de Augusto Pinochet (1979-1990) y que es seguido por cuatro gobiernos democráticos (19902010) liderados por "La Concertación de Partidos por la Democracia" (coalición de centroizquierda ${ }^{2}$. El hito de cierre del análisis es la promulgación de la Ley General de la Educación (LGE) el año 2009. En esta ley se robustece el enfoque de 
la NGP y la figura de un Estado supervigilante (o "Estado evaluador"), entendido como un árbitro del mercado escolar.

El análisis se basa en la revisión de los discursos oficiales de la época (en total 82 textos), con la limitante de excluir las controversias internas en la producción de la política. Los textos examinados incluyen: cuentas públicas anuales de los Presidentes, los discursos de los Ministros de Educación de inauguración del año escolar, los discursos presidenciales al presentar o aprobar un proyecto de ley en la materia, sumado a otros escritos relevantes de cada período. Los ejes analíticos son: i) relación Estado - mercado; ii) privatización y descentralización; iii) curriculum, evaluación y rendición de cuentas; iv) rol de las familias; y v) equidad, inclusión y educación pública.

El artículo se divide en tres secciones, que corresponden a los tres períodos identificados. Primero, el surgimiento del Estado subsidiario y del mercado educativo bajo el régimen militar (1979 a 1990), época en que germina un sistema de competencia mercantil, junto a una evaluación estandarizada ideada como mecanismo de regulación de la calidad escolar. Segundo, los primeros dos gobiernos de la Concertación (1990-2000) que mantienen el esquema anterior, combinado con un Estado compensatorio en el escenario de un sistema escolar altamente deteriorado e inequitativo. Tercero, la etapa siguiente del mismo conglomerado político (2000-2009) en que madura el modelo de NGP con una nueva matriz institucional de evaluación, inspección y rendición de cuentas.

\section{Régimen militar 1979-1990: la utopía neoliberal puesta en marcha}

Tras el golpe de Estado al gobierno socialista de Salvador Allende el 11 de septiembre de 1973 sobrevienen 17 años de dictadura cívico-militar presidida por Augusto Pinochet. Este régimen transforma radicalmente el modelo político-económico del país, inspirado por la doctrina neoliberal de Milton Friedman. En los primeros años de gobierno (1973 a 1978), sin embargo, no se impulsan reformas estructurales, pues hay una disputa soterrada entre sectores pro-mercado y vertientes nacionalistas que están por mantener un mayor grado de control estatal. (NUÑEZ, 1984) Aunque esta tensión perdura durante el régimen, en 1979 el fragmento neoliberal, liderado por los "Chicago boys"3, domina el campo de producción de la política, lo que le permite llevar a cabo las reformas de la época. Los principios orientadores del llamado "experimento chileno" son el término del Estado desarrollista de bienestar y el intento de hacer realidad la utopía del libre mercado, en defensa de la libertad individual y el libre emprendimiento. 
La reforma en educación se anuncia en la "Directiva Presidencial de la Educación Nacional" y en una carta escrita por A. Pinochet al Ministerio de Educación del momento, Gonzalo Vial, ambos textos publicados en el diario El Mercurio (6 de marzo, 1979). Dicha reforma reemplaza el modelo de Estado Docente ${ }^{4}$, proveedor mayoritario de la educación escolar (es decir, "la vieja gestión pública”), por un Estado subsidiario y una regulación mercantil. Desde principios del siglo XIX existe en el país la libre elección de los padres y un segmento de educación privada subvencionada, provista en su mayoría por instituciones Católicas. No obstante, lo novedoso de la reforma de la década de los 80 s es que introduce una organización competitiva al sistema escolar.

Las principales medidas durante este período son: i) incentivar la libre entrada de instituciones privadas a la educación (incluidas aquellas con fines de lucro); ii) transferir la administración centralizada de los establecimientos públicos a los municipios; iii) sustituir un financiamiento estable de las escuelas por uno competitivo por alumno (voucher) y equiparar el subsidio del sector privado al de las escuelas fiscales; iv) cambiar el estatus docente de funcionario público a un régimen de empleado que negocia individualmente sus condiciones; v) crear una prueba nacional estandarizada. Lo anterior transcurre en una atmósfera de represión política y control curricular.

Las transformaciones realizadas en estos años inician un nuevo ordenamiento del sistema escolar del que surgen los primeros cimientos de la NGP.

\section{El Estado subsidiario y el antiestatismo}

Al anunciar los cambios venideros en la Directiva Presidencial, la reforma en educación se construye a partir de una narrativa de crisis y de urgencia frente al "grave problema" de la educación pública y el fracaso del Estado proveedor. Este relato es parte del discurso antiestatista del régimen, hilo conductor en diversos textos, en el que se critica un Estado "inoperante" y burocrático, junto a una comunidad de padres desinformada y pasiva. Este discurso de crisis otorga justificación a los ejes rectores de la reforma educacional: Estado subsidiario, expansión del sector privado y supremacía de la libertad de enseñanza.

La educación, en este cambio de paradigma, se ubica en la esfera privada de la familia y es el rol del Estado proteger esta libertad individual, lo que viene a reemplazar el ideario republicano de la educación como un derecho y un bien social. (RUIZ, 2010) Son los padres los que saben "maximizar sus bienes" y elegir la mejor opción para sus hijos, como lo expone el Ministro de Educación Alfredo Prieto (1983, p. 13-16). Esto queda además estipulado en la Ley Orgánica Constitucional de la Educación (LOCE), en la que se afirma que: "Corresponde, preferentemente, a los padres de familia el derecho y el deber de educar a sus 
hijos;"; y al Estado "resguardar especialmente la libertad de enseñanza" (LOCE, 1990 , artículo $2^{\circ}$ y $\left.3^{\circ}\right) .^{5}$

Bajo este prisma se requiere minimizar el Estado, pues es visto como una amenaza a la libertad individual (ver la "Declaración de Principios del gobierno”, 1974). De ello deriva que en la Directiva Presidencial se define que el Estado se debe consagrar "solo a tareas normativas y fiscalizadoras" (6 de marzo, 1979), mientras se descentraliza y privatiza la provisión de la educación escolar.

Los discursos de la época promueven con fuerza la propagación de la educación privada y la delimitación de la pública. En palabras de Pinochet "la posibilidad que el Estado expanda aún más su labor educacional debe considerarse improbable [...] por consiguiente, se estimulará con energía la ayuda que el sector privado presta" (Carta al Ministro, 1979). La educación privada se visualiza como una provisión que supera la calidad de la pública, pues responde a los principios de libertad de elección, emprendimiento y eficiencia. Los resultados son bastante efectivos; en 1979 la educación privada representa un 19\% del total de la oferta, mientras en 1990 aumenta a un 42\%. (MINEDUC, 2001)

\section{La fórmula del mercado: Competencia, privatización y segmentación}

El pensamiento político en los discursos del régimen mantiene el supuesto básico de la teoría del libre mercado: la competencia entre diversos proveedores propicia la calidad y eficiencia del servicio. Es el mercado, esto es la agregación de las decisiones individuales de los padres, el que estimula la calidad del sistema; no la intervención del Estado. En palabras de Gerardo Jofré, asesor del régimen militar, un diseño competitivo, "sin asfixias del Estado" y con "completa libertad", impulsa y expande la creatividad de los individuos y los buenos servicios, mientras los proveedores ineficientes tienden a desaparecer (1988, p. 210). Un escenario con una disminuida regulación estatal se concreta en la Constitución de 1980 al puntualizar que "La libertad de enseñanza no tiene otras limitaciones que las impuestas por la moral, las buenas costumbres, el orden público y la seguridad nacional" (artículo 11\%).

Los antivalores de este enfoque son la estabilidad laboral y un financiamiento seguro. Jofré (1988, p. 209) sostiene que los individuos requieren incentivos externos que generen sentido de riesgo, de pérdida - particularmente financiera -, como un dolor pecuniario, para movilizar positivamente los actores. En los discursos no hay alusión alguna a compromisos éticos, personales, ni profesionales.

Estos cambios se dan junto a un Estado que garantiza como derecho - solamente - la educación primaria. Mientras tanto, la educación secundaria y 
especialmente la superior "constituye una situación de excepción (...) y quienes disfruten de ella deben ganarla con esfuerzo" (A. Pinochet, Carta al Ministro, 1979). Bajo esta racionalidad se permite que los establecimientos cobren a las familias, con excepción de la educación pública primaria.

La inequidad y la segmentación social, desde esta perspectiva, no son un problema. Por el contrario, la segregación del sistema escolar contribuye a identificar la capacidad de pago de las familias y a delimitar la educación gratuita a los sectores de extrema pobreza, reduciendo por ende el gasto fiscal. (ver JOFRE, 1988 , p. 212-215) El decreto de esta medida denominada "financiamiento compartido" (1980), no obstante, recién comienza a aplicarse en 1988, y en efecto no se expande hasta 1993 con la reformulación a la ley.

\section{El incipiente comienzo del Estado evaluador}

Se establece en esta época un curriculum mínimo nacional de carácter "humanista cristiano", que forme "buenos trabajadores, buenos ciudadanos y buenos patriotas" (A. Pinochet, Carta al Ministro, 1979). El curriculum adquiere bajos grados de estructuración con el objeto que exista "libertad curricular", aunque hay un control ideológico del régimen de "despolitización". Se dibuja, de este modo, una alianza entre el pensamiento neoliberal y el conservador, sustituyendo la tradición de un Estado republicano laico.

En términos de políticas de evaluación, se pone fin a las "pruebas locales" que eran construidas por grupos de docentes a nivel territorial ${ }^{6}$, y se introduce, en 1982, una evaluación estandarizada censal que derivó en el Sistema de Medición de la Calidad Educativa (SIMCE). Esta medida es comprendida como una pieza imprescindible para la concreción de la modernización del sistema educativo, pues genera un indicador "comparativo de la calidad" educativa. (PRIETO, 1983, p. 95) La difusión pública de los resultados de cada establecimiento queda estipulada en la LOCE (Artículo $19^{\circ}$ ), aunque no se alcanza a implementar en este período.

En las Actas de la Junta de Gobierno y en el Informe de la Comisión Conjunta para la redacción de la LOCE (17 y 25 octubre, 1988) se evidencia que, desde su génesis, la prueba nacional SIMCE se piensa para distintos fines. Se entiende que ofrece información "objetiva", que sirve como insumo para que los padres puedan ejercer su "libre elección" de entrada y salida a los establecimientos escolares, como responsables y primordiales interesados de la educación de sus hijos. Adicionalmente, la evaluación nacional se plantea con el objeto de ser usada por educadores con fines pedagógicos y también para controlar, desde el Estado, el cumplimiento del curriculum mínimo. 
Esta última hebra de una política de evaluación estandarización, a pesar de los principios de libertad individual preponderantes en el gobierno, ubica, de forma incipiente, un control desde el Estado y la idea de que existe una calidad objetivada, como un bien supraindividual. En palabras del Ministro de Educación Prieto: "Se podrá demostrar [con la prueba] la verdad o falsedad de una serie de afirmaciones que se escuchan frecuentemente acerca de la calidad de nuestra educación" (1983, p. 97), logrando que, como afirma Jofré (1988), "las normas sobre libertad de enseńanza puedan operar en forma adecuada" (p. 95-96, énfasis propio).

Lo que parecía un ideario de un "mercado salvaje" y un Estado minimizado, contiene paradojalmente una visión de libertad de la enseñanza que debe ser normada por el Estado. El estudio de este período muestra que desde el inicio del modelo, el control curricular y evaluativo son ingredientes fundamentales en el diseño (aunque el grado de desarrollo técnico de los instrumentos es aun inmaduro en la época). Estos son los cimientos de una gobernanza "a la distancia".

\section{La Concertación 1990-2000: el Estado compensatorio de los vacíos del mercado}

Con la vuelta a la democracia "la Concertación" asume el poder por cuatro períodos presidenciales consecutivos durante 20 años (1990 a 2010). A los partidos de esta coalición de centroizquierda los une haber sido opositores a la dictadura militar. No obstante, bajo estos gobiernos se mantiene, en términos generales, el Estado subsidiario y las políticas neoliberales heredadas y predomina la convicción de mantener una "economía abierta" y "políticas de crecimiento". Esta fase, conocida como "La transición”, implica una democracia limitada, pues el régimen militar condiciona la vuelta de la democracia con la preservación de la Constitución Política de 1980 y de un conjunto de otras leyes constitucionales, como la LOCE en materia educacional ${ }^{7}$. La estrategia política de la Concertación, conocida como "la política de los consensos", es conservar las transformaciones estructurales realizadas bajo la dictadura y conciliar los cambios venideros con los partidos políticos de derecha, con el fin de evitar cualquier ruptura institucional. (MOULIAN, 1997)

La producción de la política en el campo de la educación no dista de este marco general de gobierno. Durante los ańos 80s existen centros académicos disidentes a la dictadura, como es el Centro de Desarrollo en Investigación y Educación (Cide), la Facultad Latinoamericana de Ciencias Sociales (Flacso) y el Programa Interdisciplinario de Investigaciones en Educación (PIIE), que preparan el diseño de políticas educativas que luego serían llevadas a cabo por los gobiernos de la Concertación. Esta producción político-intelectual tuvo un carácter más 
pragmático que de pensamiento crítico, como explica Picazo (2011). Bajo la dictadura se permite la existencia de estos centros, pero bajo un contexto de censura respecto a todo aquello que pudiese parecer cercano al marxismo. Estos centros, además, son financiados con fondos internacionales con la expresa misión de preparar y consensuar lineamientos políticos en la materia para el restablecimiento de un futuro gobierno democrático. (ver, por ejemplo, COX, 1985; PIIE, 1989)

Los gobiernos de esta década mantienen el diseño privatizador, competitivo y descentralizado iniciado en el período anterior, y se avanza gradualmente en medidas de evaluación estandarizadas e incentivos. Junto a ello, se introducen nuevas hebras en este tejido.

Durante la dictadura, debido a la reducción del gasto fiscal, las condiciones de los docentes y de los establecimientos están muy deterioradas. Frente a ello, el nuevo gobierno impulsa una política de aumentar el gasto público y privado, y toma diversas medidas - universales y de acción compensatoria - para el mejoramiento de los procesos pedagógicos y de las condiciones de los establecimientos ${ }^{8}$. Se entregan importantes insumos para infraestructura, textos escolares, materiales pedagógicos y tecnológicos, y fondos para la creación de proyectos educativos en las escuelas; se lleva a cabo una reforma curricular; se realizan capacitaciones masivas a los docentes y se extiende la jornada escolar de media a jornada completa. En efecto, la inversión pública aumentó de un 2.4\% de PIB en el año 1990 a un 4.1\% al año 2000. (MINEDUC, 2001) ${ }^{9}$ Adicionalmente, se crea un Estatuto Docente que establece regulaciones laborales específicas para el profesorado, favoreciendo particularmente la estabilidad del sector público.

Las medidas descritas se articulan bajo la narrativa de una "Reforma Educacional". Emerge un discurso pedagógico que apunta a cambiar prácticas tradicionales de la enseñanza ("enseñar a aprender a aprender"), junto a formar capital humano para que el país se integre y compita con éxito en una economía abierta y globalizada, acorde a la sociedad del conocimiento y a un sistema democrático. Ello es parte de una racionalidad política post-consenso de Washington, que enaltece la importancia del Estado para el desarrollo económico y social. Esta visión estuvo fuertemente influenciada por el Banco Mundial - que financia parte importante de las políticas de los $90 s^{10}-y$ por la Comisión Económica para América Latina y el Caribe (Cepal). (GARCIA HUIDOBRO; FERRADA; GIL, 2014; HERRERA; REYES; RUIZ, 2015)

\section{El mantra del "equilibrio": entre la libertad y el Estado}

Los discursos del gobierno expresan el deseo de establecer "equilibrios" y una "responsabilidad mixta" entre las libertades individuales y las regulaciones del Estado. Se perfila un discurso ecléctico, en sintonía con el surgimiento de la "So- 
cialdemocracia renovada" y la "Tercera vía”. (GIDDENS, 1998) La racionalidad política de este período defiende el valor de la libertad de enseñanza y la mantención de la descentralización del sector público impulsadas bajo la dictadura y, a su vez, propone un Estado activo que invierte, orienta y apoya a los establecimientos educativos.

"Las fuerzas espontáneas del mercado y la competitividad, por sí mismas no resuelven todos los problemas", sostiene el Ministro Ricardo Lagos (inauguración del año escolar, marzo, 1992). Para los gobiernos de la Concertación el financiamiento a la demanda y la privatización no son medidas problemáticas, ofrecen libertades individuales, por tanto, satisfacen un lado de la balanza del equilibrio. El problema se sitúa en el otro lado de la balanza, en que falta direccionalidad y soporte Estatal para asegurar el desarrollo de capital humano, la formación ciudadana y una mayor equidad educativa.

Uno de los impulsores de estas políticas desde el Ministerio de Educación, Cristian Cox (2003), defiende que, si bien existen continuidades con la reforma de los años 80s, en términos globales el diseño de la Concertación refiere a un nuevo paradigma en la política educacional. El autor sostiene que bajo estos gobiernos se sustituye un Estado minimalista-subsidiario, por un "Estado promotor" que "contrabalancea al mercado como regulador del sistema". (COX, 2003, p. 20; ver también NÚNEEZ, 1995; GARCÍA-HUIDOBRO, 1999) Desde esta aproximación, cobra especial relevancia la realización de programas universales y de discriminación positiva, y la definición de marcos nacionales de curriculum y evaluación.

\section{La desaparición de lo público}

Dentro del ideario del equilibrio, se yergue la idea de la "igualdad de trato” entre el sector público y privado. Como sostienen Brunner y Cox (1995, p. 28) - ambos integrantes de gobierno - al referirse a las políticas del momento, se "desdramatiza" el divisor público/privado. Ello conlleva que el Estado continúe entregando "sin discriminación" la misma subvención y beneficios al sector privado y público. El Estado mantiene desde la dictadura un rol no preferente hacia el sector público. Las categorías público/privado se desvanecen, mientras cobra sentido - en función de las políticas de acción compensatoria - la división entre la educación gratuita o educación "a la que acceden los más pobres”, versus la educación pagada o de los "más privilegiados". No hay un relato respecto a lo público en los discursos analizados; no aparece como un bien social en sí mismo, distintivo del sector privado. Aunque tampoco se promueve el sector privado como un mejor servicio que el público, como ocurrió durante el régimen anterior. 
En 1993 se decreta una ley que permite el cobro a las familias en el sector subvencionado ("financiamiento compartido"), ajustando la normativa de 1980, y crea incentivos tributarios para la realización de donaciones de empresas a la educación. En estos años emergen discursos oficiales respecto a la necesidad de aumentar tanto el gasto público como el gasto privado. "Bienvenido un creciente aporte privado y comunitario a la educación" dice el Ministro Lagos en un discurso de inauguración del ańo escolar (marzo, 1992). En la misma línea, el Ministro Molina arguye que se debe "aprovechar plenamente el esfuerzo convergente del Gobierno, las familias y los empresarios" (inauguración del año escolar, marzo, 1995). Esta medida se defiende con fuerza en el "Informe de la Comisión nacional para la modernización de la educación"11 (BRUNNER, 1994) encargado por el Presidente Eduardo Frei. Sin embargo, esta es una medida que suscita críticas internas en el Ministerio de Educación, lo que evidencia la existencia de fracciones dentro del gobierno entre aquellas más liberales y aquellas más "estatistas". (COX, 2003; GARCÍA-HUIDOBRO, 2002)

Como consecuencia de las políticas anteriores, el sector particular subvencionado, con el pasar del tiempo, comienza a obtener una ventaja significativa frente al sector público. Los establecimientos privados subvencionados pueden lucrar - más del 85\% persigue estos fines (ELAQUA; MARTINEZ; SANTOS, 2011) - y un 64\% del sector puede cobrar una mensualidad a las familias (MINEDUC, 2014), sumado a una baja regulación respecto a los procesos de selección y expulsión del alumnado, que se vuelven prácticas recurrentes en este tipo de establecimientos. (CARRASCO et al., 2014)

Por otra parte, la comprensión de equidad se circunscribe a que todos los establecimientos tengan igual calidad educativa, también denominada "calidad distribuida con equidad". Desde este enfoque, el esfuerzo del Estado es apoyar con especial ahínco a los sectores más desventajados para acortar "la brecha de la calidad educativa". La finalidad está puesta en maximizar las "oportunidades" individuales de los ciudadanos para desarrollarse exitosamente en estudios superiores y en el mercado laboral. Mientras tanto, el discurso predominante se aparta del ideario de la educación como un derecho social y de las preocupaciones explícitas vinculadas a una educación pública e inclusiva. (GARCÍA HUIDOBRO et al., 2014)

Las medidas compensatorias de esta década, aunque pudiesen implicar relevantes contribuciones a la educación en sectores de mayor pobreza, son insuficientes y mantienen un sistema desigual. Más aún, las medidas impulsadas - como el financiamiento compartido - no solo no frenan la segmentación social en el sistema educativo y el declive de la educación pública, sino que la intensifican. (VALENZUELA; BELLEI; DE LOS RIOS, 2014) 


\section{Continuidad e intensificación de las políticas de evaluación e incentivos}

La definición del curriculum nacional es una importante misión del Ministerio de Educación que se establece en la LOCE. La Concertación le da una función estructurante al curriculum, bajo la lógica del "Estado proactivo". A la vez, la noción de "libertad curricular" de la dictadura se mantiene, renombrada como "descentralización curricular". La narrativa del momento enfatiza respecto a la contextualización del curriculum, la reflexión docente y la participación de las comunidades escolares, lo que cobra especial sentido en un contexto post-dictatorial. Sin embargo, en la práctica el curriculum adquiere altos grados de centralismo, por ende, este énfasis es más discursivo que real.

En esta década se mantiene y desarrolla adicionalmente otra hebra que emana de la dictadura referida a las políticas de evaluación estandarizada. La evaluación nacional SIMCE se preserva y desde 1995 se comienzan a difundir sus resultados en los medios (estipulado en la LOCE). En 1996, adicionalmente, se crea el Sistema Nacional de Evaluación Desempeño (SNED), el que liga el desempeńo escolar en definidos indicadores de calidad con la entrega de incentivos (bonos salariales). Estas medidas están acompañadas de una racionalidad política que promueve, aunque de forma aún tímida, medidas de rendición de cuentas por desempeño. De hecho, en los documentos del Ministerio de Educación y en su página web se define como principio de la reforma pasar "De regulaciones exclusivamente burocrático-administrativas del sistema, a énfasis en regulaciones por incentivos, información y evaluación [...]”. (MINEDUC, 1998, p. 113)

A modo de síntesis, en esta década se agregan nuevas aristas a la constitución de la NGP. Las combinaciones trazadas entre el Estado y el mercado no significan reformas estructurales ni ponen en tensión el modelo de base diseńado en los ańos 80. Esta fase, no obstante, significa un giro en la compresión del Estado como soporte institucional. El Estado no es una amenaza al "libre mercado", como es entendido bajo el régimen dictatorial, sino que el Estado/mercado son vistas como esferas complementarias, donde el primero juega un rol clave en el desarrollo económico, la "igualdad de oportunidades” y la formación democrática del país, tarea que no puede ser suplida por el mercado.

\section{La Concertación 2000-2009: consolidación del Estado supervigilante}

En esta tercera etapa hay una maduración de la NGP con una lógica de gerencialismo, en la que la escuela debe estar orientada a lograr y demostrar un 
desempeño de "calidad". El acento de la política ya no está en lo que el Estado le entrega a la escuela, sino en lo que la escuela le entrega al Estado. Es un Estado fuerte, no por invertir, apoyar y promover programas específicos, sino por estandarizar, evaluar, demandar y sancionar.

Desde inicios del 2000 se distingue un nuevo tono narrativo respecto del período anterior. Se desvanecen los discursos vinculados a la participación y "descentralización curricular" y aparece de modo más evidente, lo que venía gestando en la etapa previa: un marcado centralismo curricular y una agenda de evaluación y estandarización.

El nuevo acento es respuesta a una percepción de crisis. A fines de los 90s, a pesar del aumento en la inversión fiscal y de haber llevado a cabo una reforma educativa, los puntajes nacionales del SIMCE no evidencian un incremento significativo, ni se revierten las inequidades en los resultados. Las preocupaciones del gobierno tienen un claro foco: "más y mejores aprendizajes". La Ministra Mariana Aylwin en su primer discurso de inauguración del año escolar señala “[...] tenemos que poner más atención en los resultados escolares" lo que significa “impulsar una nueva cultura de la excelencia [...]”. (marzo, 2001).

Desde esta racionalidad, medidas de rendición de cuentas se comienzan a incorporar en los programas compensatorios ("Escuelas críticas", "Liceos prioritarios"), en dispositivos de gobierno como el "Marco para la buena dirección" y el "Sistema de aseguramiento de la calidad de la gestión escolar" (2005); además de aumentar la frecuencia de las pruebas nacionales, posterior a la "Comisión SIMCE” (2003). Paralelamente se elabora la Ley de Subvención Escolar Preferencial (SEP), con el convencimiento que los recursos estatales deben entregarse a cambio de resultados evaluativos. En el mensaje presidencial del proyecto de Ley, el Presidente Lagos alerta que hasta el momento la entrega de recursos ha sido "sin importar lo que se haga con ellos ni los resultados que se obtienen" (18 de octubre, 2005). Esta ley, posteriormente aprobada en el año 2008, es la primera que incorpora de modo más evidente un esquema de rendición de cuentas, con la entrega de un subsidio escolar por cada alumno proveniente de contextos de desventaja social a cambio del cumplimiento de metas e indicadores establecidos por el Estado. ${ }^{12}$

En el año 2006 se da un nuevo giro. Entran al escenario los estudiantes con masivas protestas y una extensiva crítica al esquema neoliberal heredado de la dictadura militar. Este movimiento, conocido como el "movimiento pingüino"13, abre un debate público. Mientras el modelo de mercado escolar se había aceptado y naturalizado durante los gobiernos de la Concertación, los estudiantes cuestionan sentidos comunes instalados en el país, como la desregulación del sector privado, la existencia de establecimientos subvencionados con fines de lucro, el cobro por la educación y la inequidad del sistema. Las pancartas dicen "La educación no se 
vende", "No más mercado", "Educación pública, gratuita y de calidad", críticas que hacen eco en la ciudadanía en general. (FALABELLA, 2008) A ello se suma un acumulado de investigaciones que cuestionan la contribución de un esquema competitivo y los supuestos beneficios del sector privado-subvencionado por sobre el sector público. (BELLEI, 2007; OCDE, 2004)

En esta atmósfera de crisis e incertidumbres, el gobierno elabora como solución un Estado supervigilante, árbitro del mercado escolar, con un radical sistema de inspección y rendición de cuentas. Es una versión socialdemócrata de la NGP que hace eco con la noción de un "Estado protector" y que a la vez permite mantener una regulación competitiva, en sintonía con las políticas que circulan a nivel global (especialmente en países anglosajones) y con las recomendaciones del Banco Mundial y la OCDE.

La edificación de la NGP en esta fase se funda sobre un consenso entre la Concertación y la derecha opositora: el "experimento chileno" de la década del 80 fracasó. La calidad no se autorregula vía la elección de los padres y la competencia entre proveedores. Este es el punto de acuerdo entre ambos conglomerados políticos para aprobar el nuevo esquema. De hecho, hay múltiples escritos que promocionan el proyecto de la NGP en el país, elaborados por intelectuales de derecha (por ejemplo, BEYER, 2001; FONTAINE; EYZAGUIRRE, 2001) y por quienes han formado parte de los gobiernos de la Concertación (por ejemplo, TRAVERSO, 2004; MONTT, et al., 2006; VANNI; BRAVO, 2010), como también textos co-escritos por autores de ambos conglomerados (LARROULET; MONTT, 2010; SANTANDER; BRUNNER; et al., 2002).

En 2009, respondiendo a la demanda estudiantil por derogar la LOCE, esta se reemplaza por la Ley General de Educación (LGE). Esta ley, conservando el esquema de mercado escolar, crea una nueva matriz institucional - la Superintendencia y la Agencia de la Calidad de la educación -, que conlleva un sistema de evaluación, inspección, clasificación de los establecimientos según su nivel de desempeño y de difusión de los resultados. Dichos resultados, a la vez, están ligados a premios y sanciones, entre las que se incluye el eventual cierre de una institución escolar por rendimiento insatisfactorio. Posteriormente, en 2011, esto se detalla en la ley de "Sistema Nacional de Aseguramiento de la Calidad de la Educación".

\section{El Estado salvador del fallido mercado}

Luego del movimiento pingüino el discurso oficial captura tácticamente las críticas y demandas de los estudiantes en función de canalizar y justificar el robustecimiento de políticas de evaluación e inspección, aludiendo a que "necesitamos más y mejor Estado", en palabras de la Presidenta Bachelet (inauguración 
del año escolar, marzo, 2008). Ejemplo de estos discursos son los siguientes fragmentos:

\begin{abstract}
Entregar una educación de mala calidad es una estafa y eso hoy día nadie lo controla. La educación básica, media y superior se ha comercializado. Se puso la libertad de enseñanza por sobre el derecho a la educación. Deben estar al mismo nivel. Los estatistas dicen que todo lo debe controlar el Estado, los otros sostienen que el mercado regula. Yo estoy por mayor libertad, pero con un control mucho más fuerte del Estado - no del gobierno - sobre la calidad. (Ministro Martin Zilic, entrevista en El Mercurio, 11 de junio, 2006, énfasis propio).

[El nuevo marco legal debe] consagrar el derecho de todo ciudadano a una educación de calidad, que no se contrapone con la libertad de enseñanza. El Estado pasará a ser un verdadero garante de la calidad de la educación subvencionada, pública y privada. [...] queremos que la educación de calidad sea un derecho, que los ciudadanos puedan hacer efectivo mediante un recurso de protección ante los Tribunales de Justicia, si fuese necesario. Lo dije en el Congreso Pleno y lo reitero: lo que estamos haciendo en este gobierno, es sentar las bases de un Estado al servicio de las personas (Presidenta Bachelet, cadena nacional, 1 junio, 2006, énfasis propio).
\end{abstract}

Los extractos ilustran que la educación más que entenderse como un derecho social, se entiende como un derecho individual vinculado a recibir un servicio de calidad. Se reconocen falencias o "estafas" en el mercado y que es inefectivo dejar la responsabilidad de demandar calidad en manos de las familias. La solución, consistente con la aspiración del equilibrio de la Concertación, es perfilar un Estado árbitro que orienta y regula a los proveedores públicos y privados en un esquema de libre elección. Ello se estipula en la LGE, en la que se señala que el Estado tiene el deber de resguardar la libertad de enseñanza y el derecho de los padres de escoger la educación de sus hijos (artículo 7o) y, a su vez, de "asegurar" la calidad del sector público y privado (artículo $6^{\circ}$ ) "al servicio de las personas", como dice la Presidenta.

\title{
Gestión orientada por resultados
}

Aparece con vigor en esta década un enfoque de "gestión orientada a resultados", nutrido por la teoría de las escuelas eficaces. Los supuestos de la política es que los establecimientos tienen autonomía en los modos de efectuar su gestión y, a la vez, son responsables de su desempeño y deben rendir cuenta por ello. Esto queda decretado en el artículo $3^{\circ}$ y $4^{\circ}$ de la LGE. 
Se busca promover en las escuelas, según los documentos de gobierno, las "características presentes en escuelas efectivas y sustentarlas en el tiempo", lo que involucra "[...] sistematicidad de sus acciones, despliegue de sus sistemas a nivel institucional, orientación a metas, revisión y mejoramiento permanente, y evaluación de resultados e impacto de sus sistemas [...]". (MINEDUC, 2005, p. 8-9) Emana una visión racional de la gestión escolar, en la que las metas medibles y evaluaciones estandarizadas componen un eje rector. Las decisiones "no deben ser al azar", sino que deben estar fundamentadas en "evidencias" derivadas de los resultados evaluativos. Lo que no se mide ni es demostrado para un externo no tiene valor, no existe. Por el contrario, los documentos y discursos oficiales realizan escasa referencia a la necesidad de una reflexión curricular docente relativa a qué se evalúa externamente y cómo ello se engarza o no al proyecto educativo local y sus principios pedagógicos y/o filosóficos.

La política exige una doble rendición de cuentas tanto hacia el Estado, como hacia las familias. De hecho, en este período se extiende la difusión de los resultados SIMCE a un sitio web y a cartillas e informes para padres. Además, se establece en la ley SEP y en la LGE que cuando un establecimiento obtenga resultados insatisfactorios se enviará una carta a todos los padres informándoles de la situación y ofreciéndoles alternativas de establecimientos próximos.

El análisis de los discursos evidencia que para los gobiernos de la Concertación el SIMCE es una herramienta de especial utilidad para el Estado, en términos de justificar y monitorear las políticas públicas, direccionar prioridades curriculares y evaluar los establecimientos. En el caso de las familias, el énfasis está puesto en que ellas tengan el derecho a estar informadas y se les insta a apoyar el trabajo educativo y a mejorar los resultados evaluativos como una "responsabilidad de todos". A diferencia de la derecha dictatorial, no se espera que la elección de las familias sea la causa que regule la calidad de la educación.

\section{Equidad, educación pública y otras hebras sueltas}

El mecanismo para asegurar la "igualdad de oportunidades", en este período, refiere centralmente a la entrega de mayores recursos focalizados en contextos de pobreza, la que está ligada a medidas de rendición de cuentas por desempeño. El Estado evaluador se ejerce con especial fuerza por medio de la SEP sobre los establecimientos que atienden alumnos provenientes de sectores más carenciados. Son las escuelas (no es Estado) las que pasan a ser las responsables de incrementar los "resultados de calidad". La Presidenta Bachelet señala: "Lo digo con toda claridad: más recursos para los niños de familias con menores ingresos, sí; pero también más rendimiento de las escuelas donde esos nińos asisten" (cuenta pública, 21 de mayo, 2006). 
Durante la mayor parte de este período se mantiene la defensa de proteger la "provisión mixta" y la educación pública se identifica con las instituciones que atienden a los sectores más desventajados socialmente y se asocia abiertamente a una oferta de baja calidad. La Ministra Yasna Provoste, por ejemplo, señala respecto del sistema público, "allí tenemos los problemas más graves de calidad [...] porque en él se atienden los grupos más vulnerables de la población” (discurso en el Encuentro Anual de Educación \& Empresa, ENEDUC, 29 de noviembre, 2007). En palabras de la Ministra Mónica Jiménez, "Debe existir una educación particular, pero también una educación pública de calidad, porque 6/7 de los niños más vulnerables del país están allî” (discurso en ENEDUC, 19 de noviembre, 2008).

Con posterioridad al movimiento pingüino, no obstante, se comienzan a levantar otras narrativas al respecto. Surge una compartida crítica referida a la segmentación social y académica en el país, junto a una ética integradora a favor de la no discriminación y de la cohesión social. Ello se acompaña con un vuelco narrativo a finales del período respecto a "una educación pública gratuita, humanista, laica, moderna y de calidad” (Presidenta Bachelet, mensaje presidencial del proyecto de la LGE, 17 de agosto, 2009). Adicionalmente, surgen voces críticas respecto al permiso de los establecimientos subvencionados a tener fines de lucro. Algunas modificaciones se realizan al respecto en la LGE, pero ninguna significa un cambio efectivo y quedan como hebras sueltas que no llegan a acuerdo dentro de la propia coalición de la Concertación. (No obstante, posteriormente se avanza en esta línea y se aprueba la "Ley de Inclusión Escolar" en 2015, que aplica gratuidad, prohíbe - con excepciones - la selección de alumnos y pone fin a instituciones con fines de lucro en la administración subvencionada.)

\section{Reflexiones finales}

El sistema educativo Chileno es un caso de estudio peculiar, pues permite examinar el paulatino tejido de la NGP que se inicia con un mercado desregulado, siguiendo las recomendaciones de la economía monetarista neoliberal, que luego transita hacia un Estado "compensatorio", que cubre los vacíos del mercado desarrollando múltiples iniciativas e inversiones en las escuelas, y que, finalmente, consolida un Estado árbitro del mercado escolar, que ejerce su control por medio de políticas de estandarización, inspección y rendición de cuentas.

Aunque en las tres fases identificadas el modelo tiene ciertos giros y énfasis específicos (Tabla 1), se preservan los cimientos de un mercado escolar y se da forma a una versión mercantilizada de la NGP, que incluye un rol subsidiario de parte del Estado, un esquema competitivo de financiamiento, un trato igualitario hacia el sector privado y subvencionado y una evaluación nacional centralizada. 


\section{Tabla 1}

Síntesis

\begin{tabular}{|c|c|c|c|}
\hline $\begin{array}{c}\text { Fase/Elementos } \\
\text { de la NGP }\end{array}$ & $\begin{array}{c}\text { Dictadura militar: } \\
1979-1990 \\
\end{array}$ & $\begin{array}{c}\text { La Concertación } \\
1990-2000 \\
\end{array}$ & $\begin{array}{c}\text { La Concertación } \\
\text { 2000-2009 } \\
\end{array}$ \\
\hline $\begin{array}{l}\text { Principios } \\
\text { orientadores }\end{array}$ & $\begin{array}{c}\text { Libertad de la enseñanza; } \\
\text { libre competencia; } \\
\text { nacionalismo }\end{array}$ & $\begin{array}{l}\text { Ideario del equilibrio } \\
\text { Estado/mercado se } \\
\text { complementan }\end{array}$ & $\begin{array}{l}\text { Continuidad años } 90+ \\
\text { Responsabilización de } \\
\text { resultados } \\
\end{array}$ \\
\hline Rol del Estado & $\begin{array}{l}\text { Estado subsidiario, } \\
\text { reducción del gasto fiscal, } \\
\text { control curricular }\end{array}$ & $\begin{array}{l}\text { Estado compensatorio de } \\
\text { los vacíos del mercado. } \\
\text { Centralismo curricular y } \\
\text { evaluativo, apoyo técnico- } \\
\text { pedagógico }\end{array}$ & $\begin{array}{c}\text { Estado supervigilante del } \\
\text { mercado; "protección al } \\
\text { cliente" }\end{array}$ \\
\hline $\begin{array}{l}\text { Privatización de lo } \\
\text { público }\end{array}$ & $\begin{array}{c}\text { Incentivos a la } \\
\text { privatización, voucher, } \\
\text { financiamiento } \\
\text { compartido, } \\
\text { municipalización } \\
\end{array}$ & $\begin{array}{l}\text { Continuidad años 80; } \\
\text { "Igualdad de trato". } \\
\text { Expande financiamiento } \\
\text { compartido: "diversificar la } \\
\text { inversión" }\end{array}$ & $\begin{array}{l}\text { Continuidad años } 80 \text { y } 90 . \\
\text { Post-2006: inicia críticas a } \\
\text { la municipalización, lucro, } \\
\text { co-pago; valoración a la } \\
\text { educación pública }\end{array}$ \\
\hline Rol de las familias & $\begin{array}{l}\text { Libre elección y salida; } \\
\text { responsabilidad individual }\end{array}$ & $\begin{array}{c}\text { Derecho a informarse y } \\
\text { elegir }\end{array}$ & $\begin{array}{c}\text { Continuidad años } 90+ \\
\text { familias deben apoyar } \\
\text { mejora de resultados }\end{array}$ \\
\hline $\begin{array}{l}\text { Políticas de } \\
\text { regulación de la } \\
\text { calidad }\end{array}$ & $\begin{array}{l}\text { Libre elección informada } \\
+ \text { evaluación (SIMCE) }+ \\
\text { control curricular }\end{array}$ & $\begin{array}{l}\text { Apoyo curricular- } \\
\text { pedagógico + evaluación, } \\
\text { difusión e incentivos } \\
\text { (SNED) }\end{array}$ & $\begin{array}{c}\text { Sistema de Aseguramiento } \\
\text { de la Calidad }\end{array}$ \\
\hline Políticas de equidad & $\begin{array}{l}\text { Focaliza recursos en } \\
\text { contextos de extrema } \\
\text { pobreza. Segregación e } \\
\text { inequidad no son } \\
\text { problemáticos }\end{array}$ & $\begin{array}{c}\text { Medidas de discriminación } \\
\text { positiva; Segmentación } \\
\text { social no aparece como } \\
\text { problema }\end{array}$ & $\begin{array}{l}\text { Continuidad años } 90 .+ \\
\text { Ley SEP. Post-2006: Ética } \\
\text { integradora, regulaciones } \\
\text { iniciales a prácticas } \\
\text { selectivas de alumnos }\end{array}$ \\
\hline
\end{tabular}

Fuente: Elaboración de la autora.

En base al análisis expuesto se destacan tres reflexiones finales.

\section{¿Continuidad o ruptura? Las ambigüedades de la centroizquierda en}

la Nueva gestión pública. Una pregunta persistente durante los gobiernos de la Concertación es si la naturaleza de la política significa, en efecto, una continuidad o una ruptura con la definida en los años 80. El trabajo expuesto en el presente artículo contribuye a responder a esta pregunta que cobra relevancia debido a la ambigüedad identitaria entre la matriz de pensamiento político de derecha y centroizquierda.

El modelo heredado ofrece asegurar principios de "libertad de enseñanza”, descentralización y eficiencia. El financiamiento a la demanda y la privatización no son un problema para la Concertación, aunque tampoco una solución. La Concertación, en consecuencia, sofistica el rol del Estado, con lineamientos curriculares, evaluaciones nacionales y medidas de rendición de cuentas, junto 
a sistemas de apoyo, especialmente en contextos de pobreza. Esta racionalidad política de "equilibrio" entre mercado y Estado logra puntos de acuerdo con los partidos políticos de derecha y permite entender los consensos que han mantenido y perfeccionado el modelo predominante.

Sin embargo, también hay matices entre ambos conglomerados políticos en términos de dónde colocan las confianzas en la regulación del sistema y del grado de profundidad de estas regulaciones. La Concertación pone su confianza centralmente sobre el campo de acción del Estado para la regulación de la calidad y equidad del sistema educativo. La derecha, por su parte, coloca la fe del mejoramiento del sistema, principalmente, sobre la capacidad del mercado, el sector privado y la elección/salida de los padres.

Otra diferencia se encuentra en que la Concertación, especialmente post 2006, demanda mayores niveles de regulación a la calidad y equidad en cuanto a mayores barreras de entrada de los agentes privados (deben ser entes sin fines de lucro) y propone restringir las prácticas de selección/expulsión de alumnos. Se trata de una visión contrapuesta a la defensa de la libertad de enseñanza y libre emprendimiento de los partidos de derecha. En consecuencia, aunque existen acuerdos entre los conglomerados de derecha y de centroizquierda con relación a la estructura cardinal del modelo, existen disputas respecto a los delicados equilibrios entre el mercado y las regulaciones del Estado y hay distintas confianzas y subjetividades respecto al modelo en cuestión.

El Estado supervigilante y la protección al cliente. El caso chileno evidencia que la mercantilización de la educación ha requerido de un rol clave de parte del Estado. Más que un Estado mínimo, éste ha desencadenado en un Estado mayúsculo, que vigila y direcciona el sistema educativo y ejerce de árbitro sobre una red de proveedores públicos y privados. El Estado bajo este esquema no ha disminuido su poder, sino que ha cambiado los modos de ejercer el poder "a la distancia”. Este modelo, además, implica una nueva racionalidad política sustentada en una filosofía de mercado en la que el Estado debe garantizar la protección al consumidor, apartándose de una compresión de la educación como un derecho social.

Es importante notar que el nacimiento de este Estado supervigilante no es una invención que aparece con los cambios legislativos post-2006 (como han planteado autores como MARTINIC, 2010 y BELLEI, 2015). Su genealogía comienza desde los años 80 . En los inicios de la formulación del mercado escolar se idea una libertad normada, aunque con el tiempo se fue concretando y complejizando a través de nuevas narrativas y tecnologías políticas.

La consolidación de este enfoque, posterior al 2006, se funda sobre el relato de un cruel mercado, que brinda beneficios, pero que también puede ser abusivo e ineficiente, lo que se resuelve con un buen Estado que protege y defiende 
a las familias frente a este mercado. Es un Estado salvaguardia de las fallas del mercado. Sin embargo, este relato es una dicotomía ficticia. Las reformas legales en este período implican la ampliación de dispositivos de control, de competencia y de diferenciación en el mercado. El diseño de la política, en efecto, significa una dualidad Estado-mercado en la que ambas esferas se potencian mutuamente.

La matanza de la educación pública. Luego de una férrea promoción de la educación privada y un discurso antiestatal durante la dictadura, los gobiernos de la Concertación mantienen la política de equiparación entre el sector público y privado, bajo el lema de "igualdad de trato". Ello es parte del mantra del equilibrio de la Concertación entre la igualdad y el derecho, lo público y lo privado, el mercado y el Estado (ver, por ejemplo, BRUNNER, 1994), conocido como el "sistema mixto chileno". La semántica de lo "público" se amplía incluyendo lo estatal y lo privado, sin distinción. Si bien la Concertación opta por una postura aparentemente neutral, la conjunción de las políticas, en un contexto de mercado (con opción de co-pago), produce una lenta matanza a la educación pública del país.

El nudo neurálgico de la Concertación es la ilusión de ensamblar sinérgicamente estos principios dicotómicos y negar la dimensión conflictiva de este esperado equilibrio. En la práctica, estos principios tienen una relación problemática en el campo político y han dominado unos sobre otros. Esta política resulta en un abandono - más o menos intencionado - de la defensa de lo público y del derecho a la educación como un bien social colectivo.

Como consecuencia, Chile cuenta con uno de los sistemas escolares más segmentados del mundo (DUPRIEZ; DUMAY, 2011), con una educación pública de apenas un 37.5\% de la matrícula al año (MINEDUC, 2014), y hasta ahora no hay evidencia consistente respecto de los beneficios esperados de las políticas de rendición de cuentas. (FALABELLA; OPAZO, 2014; FALABELLA; DE LA VEGA, en prensa)

Luego del año 2010, la implementación del Sistema de Aseguramiento de la Calidad (2011) ha continuado ampliando y complejizando los dispositivos de inspección y evaluación, mientras se comienza a aplicar la Ley de Inclusión Escolar (2015) en paralelo con la conservación del mercado como regla inmutable. Estos cambios generan nuevas contradicciones en un relato misceláneo entre inclusión y rendición de cuentas por resultados. Las movilizaciones estudiantiles se mantienen y alzan el argumento de "la falsa reforma que mantiene el mercado", que se acompaña de críticas a la NGP ${ }^{14}$. En este escenario, la permanencia del mercado, el rol de la educación pública y las combinaciones de la NGP como mecanismo de privatización endógena a la educación subvencionada siguen siendo un debate abierto. 


\section{Notas}

1. Apoyo financiero: Fondecyt, proyecto n. 11140302, Gobierno de Chile.

2. Compuesto por los siguientes partidos políticos: la Democracia Cristiana, Partido Radical, Partido por la Democracia, Partido Socialista.

3. Grupo de economistas de la Pontificia Universidad Católica, posteriormente formados por Friedman en la Universidad de Chicago. Su base ideológica está plasmada en el documento "El Ladrillo. Programa económico del régimen militar", el cual se termina de escribir semanas antes del golpe militar.

4. Este modelo está presente desde la segunda mitad del siglo XIX y, especialmente, desde el año 1920 en que se aprueba la Ley de Instrucción Primaria Obligatoria.

5. Igualmente en la Constitución de 1980 se establece la libertad de enseńanza y de la elección de los padres (artículo $10^{\circ}, 11^{\circ}$ ).

6. Ver Gysling (2015), quien hace un análisis histórico de las políticas de evaluación en el país.

7. Cualquier cambio legislativo requiere un acuerdo entre el gobierno y la derecha, pues se exige la aprobación de los 2/3 del parlamento. De hecho, la Constitución creada bajo la dictadura sigue vigente al año 2015.

8. Programas emblemáticos de estos años son el "Programa 900 escuelas" y "Liceo para Todos", que focalizan el apoyo en los establecimientos ubicados en contexto de mayor pobreza y de bajo rendimiento, y los programas "Mejoramiento de la Calidad y Equidad" (MECE), de cobertura universal.

9. Aunque no se llega a equiparar al porcentaje destinado con anterioridad a la reforma del año 1981, correspondiente a un $4.9 \%$.

10. Una de las condiciones acordadas de parte del Banco Mundial para el préstamo fue mantener el sistema de financiamiento por alumno y la municipalización del sector público. (COX; ÁVALOS, 1999)

11. Este informe es el texto fundador y probablemente el más importante de la Concertación en materia educacional, ya que traza los lineamientos en educación de los siguientes 15 ańos de gobierno.

12. Estas políticas se engarzan con otras medidas similares del momento como son: la Evaluación Nacional Docente (2004), el sistema de acreditación de la educación superior (2006) y la Prueba Inicia (2008) que busca evaluar y regular los recién egresados de estudios superiores en pedagogía.

13. Alusión al uniforme de los escolares: camisa blanca y corbata oscura.

14. Ver campaña en: $<$ http://altoalsimce.cl/ $>$.

\section{Referencias bibliográficas}

BELLEI, C. Expansión de la educación privada y mejoramiento de la educación en Chile. Evaluación a partir de la evidencia. Revista Pensamiento Educativo, v. 40, n. 1, 2007, p. 285-333.

LOM, 2015.

$$
\text { . El gran experimento. Mercado y privatización de la educación chilena. Santiago: }
$$


BEYER, H. Falencias institucionales en educación: reflexiones a propósito de los resultados del TIMSS. Estudios Públicos, n. 82, 2001, p. 5-33.

BRUNNER, J. J. (Coord.). Informe de la comisión nacional para la modernización de la educación. Santiago: Ed. Universitaria, 1994.

BRUNNER, J.; COX, C. Dinámicas de transformación en el sistema educacional de Chile. Santiago, 1995. Disponible en: <http://ww2.educarchile.cl/UserFiles/P0001/File/Dinamias.pdf $>$.

CARRASCO, A. et al. Politicas de Admisión, Evolución Composicional y Efectividad Escolar de Escuelas ante la Reciente Institucionalidad que Prohíbe Seleccionar Alumnos. Informe FONIDE. Santiago: MINEDUC, 2013.

CLARKE, J.; NEWMAN, J. The managerial state. Power, politics and ideology in the remaking of social welfare. London: SAGE, 1997.

CHILE. Ley Orgánica Constitucional de la Enseñanza, nº 18.962. Diario Oficial, Santiago, 10 de marzo, 1990.

. Ley General de Educación, no 20.370. Diario Oficial, Santiago, 2 de abril, 2009.

. Constitución Política de la República, decreto oficial no 1.150. Diario Oficial, Santiago, 24 de octubre, 1980.

COX, C. Hacia la elaboración de consensos en politica educacional: actas de una discusión. Santiago: CIDE, 1985.

. Políticas educacionales en el cambio de siglo: la reforma del sistema escolar de Chile. Santiago: Ed. Universitaria, 2003.

COX, C.; AVALOS, B. Educational policies change programmes and international co-operation: The Case of Chile'. In: KING, K.; BUCHERT, L. (Eds.). Changing International Aid to Education. Global Patterns and National Contexts. Paris: UNESCO and Norrag Policy, 1999.

DUPRIEZ, V.; DUMAY, X. Les quasi-marchés scolaires: au bénéfice de qui? Revue française de pédagogie: recherches en éducation, n. 176, 2011, p. 83-100.

ELAQUA, G.; MARTINEZ, M.; SANTOS, H. Lucro y educación escolar. Claves para Politicas Públicas, n. 1, 2011. Disponible en: $<$ http://www.politicaspublicas.udp.cl/media/ publicaciones/archivos/285/Documento completo.pdf $>$.

FALABELLA, A. The Performing School: Effects of Market \& Accountability Policies. Education Policy Analysis Archives, v. 22, n. 51, 2014. Disponible en: <http://epaa.asu.edu/ ojs/article/view/1315>.

. Democracia a la Chilena: Un análisis del movimiento estudiantil y de su desenlace. Revista Docencia, n. 36, 2008, p. 5-17.

FALABELLA, A.; DE LA VEGA, F. Políticas de responsabilización por desempeño escolar: Un debate a partir de la literatura internacional y el caso chileno. Revista Estudios Públicos, en prensa, 2016. 
FALABELLA, A.; OPAZO, C. Sistema de Aseguramiento de la Calidad y procesos de mejora: Una mirada desde la gestión educativa. Informe final. Santiago: CIDE, 2014. Disponible en: $<$ http://biblioteca.uahurtado.cl/ujah/reduc/pdf/pdf/txt1107.pdf >.

FONTAINE, L.; EYZAGUIRE, B. Una estructura que presione a las escuelas a hacerlo bien. In: BEYER, H.; VERGARA, R. (Eds.). ¿Qué hacer ahora? Santiago: CEP, 2001, p. $65-111$.

FOUCAULT, M. Birth of biopolitics. (Michel Foucault: Lectures at the College De France). Basingstoke: Palgrave Macmillan, 2008.

GARCÍA-HUIDOBRO, J. E. La reforma educacional chilena. Espańa: Editorial Popular, 1999.

. Las exigencias de una política educativa equitativa. Santiago, 2002. Disponible en: <http://biblioteca.uahurtado.cl/ujah/reduc/pdf/pdf/txt998.pdf $>$.

GARCÍA-HUIDOBRO, J. E.; FERRADA, R.; GIL, M. La relación educación-sociedad en el discurso político-educativo de los gobiernos de la Concertación (1990-2009). Estudios Pedagógicos, v. XL, n. 1, 2014, p. 113-131.

GIDDENS, A. The Third Way. The renewal of Social Democracy. Cambridge: Polity Press, 1998.

GYSLING, J. The historical development of educational assessment in Chile: 1810-2014, Assessment in Education: Principles, Policy \& Practice, 2015. Disponible en: <http://www. tandfonline.com/doi/full/10.1080/0969594X.2015.1046812>.

HERRERA, J. F.; REYES, L.; RUIZ, C. El Modelo de "eficacia escolar" en Chile (19902014): ¿promesa de equidad o un nuevo modelo de privatización de la educación? Santiago: Universidad de Chile. Documento de trabajo, 2015.

JOFRÉ, G. El sistema de subvenciones en educación: la experiencia chilena. Estudios Públicos, n. 32, 1988, p. 197-237.

PICAZO, I. La metamorfosis de la regulación pública en la educación escolar en Chile: hacia un estado post-neoliberal. Rev. Pensamiento Educativo, v. 46, n. 1, 2011, p. 63-91.

PIIE. Educación y transición democrática. Propuestas de politicas educacionales, Santiago: PIIE, 1989.

PRIETO, A. La modernización educacional. Santiago: Universidad Católica, 1983.

RUIZ, C. De la Republica al mercado. Ideas educacionales y politica en Chile. Santiago: LOM, 2010.

LARROULET, C.; MONTT, P. Políticas educativas de largo plazo y acuerdo amplio en educación: El caso chileno. In: ELACQUA, G.; MARTINIC, S. (Eds.). ¿Fin de Ciclo?: Cambios en la Gobernanza del Sistema Escolar. Santiago: PUC, UNESCO, 2010, p. $19-54$.

MAROY, C. Convergences and hybridization of educational policies around 'post-bureaucratic' models of regulation. Compare, v. 39, n. 1, 2009, p. 71-84. 
MARTINIC, S. Cambios en las Regulaciones del Sistema Educativo. ¿Hacia un Estado Evaluador? En ELACQUA, G. Y MARTINIC, S. (Ed.). ¿Fin de Ciclo?: Cambios en la Governanza del Sistema Escolar. Santiago: PUC, UNESCO, 2010, p. 54-78.

MINEDUC. Reforma en marcha: buena educación para todos. Santiago: Salesianos S.A., 1998.

. Compendio Estadístico. Santiago: MINEDUC, 2001.

. Sentidos y Componentes del sistema de aseguramiento de la calidad de la gestión escolar. Santiago: Unidad de Gestión y Mejoramiento Educativo, División Educación General, Gobierno de Chile, 2005.

. Compendio Estadístico. Santiago: MINEDUC, 2014.

MINEDUC-UNICEF. Guía de Apoyo para Directoras y Directores. Educación de calidad para nuestra comunidad escolar. Santiago: UNICEF, 2005.

MONTT, P. et al. Hacia un Sistema escolar descentralizado, sólido y fuerte. El diseño y las capacidades hacen la diferencia. Santiago: MINEDUC, 2006.

MOULIAN, T. Chile anatomía de un mito. Santiago: LOM, 1997.

NEWMAN, J. Remaking governance. Peoples, politics and the public sphere. Bristol: The Policy Press, 2005.

NUÑEZ, I. Las Transformaciones de la Educación bajo el régimen militar. Santiago: PIIE, 1984.

. Hacia un nuevo paradigma de reformas educativas: la experiencia chilena. Pensamiento educativo, v. 17, 1995, p. 173-189.

OCDE. Reviews of National Policies for Education. Chile. Paris: OECD, 2004.

ROSE, N.; MILLER, P. Political power beyond the state: problematics of government. British Journal of Sociology, v. 43, n. 2, 1992, p. 173-205.

TRAVERSO, A. Las nuevas reformas que la Reforma engendra. Santiago: Fundación Expansiva, 2004.

VALENZUELA, J. P.; BELLEI, C.; DE LOS RÍOS, D. Socio-economic school segregation in a market oriented educational system. The case of Chile. Journal of Education Policy, v. 29, n. 2, 2014, p. 217-241.

VANNI, X.; BRAVO, J. En búsqueda de una educación de calidad para todos: El Sistema Nacional de Aseguramiento de la Calidad. In: ELACQUA, G.; MARTINIC, S. (Eds.). ¿Fin de Ciclo? Cambios en la Gobernanza del Sistema Escolar. Santiago: PUC, UNESCO, 2010. p. 183-205.

Recebido em 23 de julho de 2015.

Aprovado em 26 de agosto de 2015.

DOI: http://dx.doi.org/10.1590/ES0101-73302015152420 